\title{
O invasivo vazio
}

\section{The empty invasive}

Cristina Santaella Braga ${ }^{1}$

Lúcia Santaella Braga ${ }^{2}$ 


\section{Resumo}

Neste artigo, a dança indiana clássica Odissi é descrita nos seus principais atributos e, a partir da iniciativa de Martinez, é comparada ao Kabuki. Encontramos no vazio o ponto de conexão entre ambas, Odissi e Kabuki. Uma vez que a dança Odissi nos foi apresentada no contexto de uma experiência vivida, as teorizações do psicanalista Jacques Lacan sobre o zen foram de grande valia para orientar a interpretação dessa vivência, aqui compreendida à luz do inescapável vazio que caracteriza o limite do saber com que $a$ arte nos surpreende e inquieta.

Palavras-chave: Odissi; Kabuki; vazio; zen; psicanálise lacaniana

\section{Abstract}

In this article, the Indian classical dance Odissi is described in its main attributes and following the initiative of Martinez, it is compared to the Kabuki. We found the point of connection between both Odissi and Kabuki in the concept of void. Once the Odissi dance was introduced to usin the context of lived experien$\mathrm{ce}$, the theories of psychoanalyst Jacques Lacan on Zen were of great value to guide the interpretation of that experience, here understood in the light of the inescapable void that characterizes the limit of knowledge with which art surprises us.

Keywords: Odissi; Kabuki; void; zen; lacanian psychoanalisis

ISSN: 1414.5731
${ }^{1}$ Doutoranda junto ao Programa de Pós-Graduação em Artes da Cena. Universidade Estadual de Campinas (UNICAMP). São Paulo (SP). crisantaella@yahoo.com.br

2 Pesquisadora 1 A do CNPq. Profa Dra. da Pontificia Universidade Católica de São
Paulo (PUC - SP). Programa de Pós-Graduação em Comunicação e Semiótica. São Paulo (SP). lbraga@pucsp.br 
Este texto nasceu a partir de uma disciplina cursada por uma das autoras deste artigo, Cristina Santaella Braga, em julho de 2013, no programa de PósGraduação em Artes da Cena da Universidade Estadual de Campinas, disciplina esta ministrada por Marília Vieira, intitulada Zona de Contágio: O Mito e Construção Corporal do Intérprete. Condensada em uma semana, a disciplina estava voltada para que, num primeiro momento, os discípulos tivessem no corpo o contato com a dança clássica indiana Odissi, treinando pela repetição dos movimentos ensinados pela mestra. Além dos exercícios técnicos, como os e os choukas, foram ensinados trechos da coreografia tradicional de Odissi chamada Dashavatar, que significa "As dez encarnações de Vishnu".

Em um segundo momento, elaboraríamos um trabalho escrito que expusesse nossas reflexões sobre a prática experienciada. Este artigo, uma expansão do trabalho então escrito, à luz de teorias específicas a serem expostas abaixo, tem por objetivo transmitir para o leitor as consequências viscerais transpostas do corpo para o papel, em uma tentativa de escrita espiral que faça registro nas reverberações do treinamento e o que disso temos para contar.

A disciplina foi marcada por uma densidade característica da cultura oriental, na qual o tempo é o tempo da espera. Tempo vazio. Tempo a ser preenchido pelo amadurecimento que a espera corporal possibilita. E, justamente, ao pensar sobre esse tempo, tão inverso daquele do ocidente, apoio foi buscado na pesquisa realizada por Bonfitto (1994) em A Pregnância do Vazio: o ensino e a prática do Kabuki para a contextualização da dança Odissi. Nesse ponto, a pesquisa sobre o Oriente e o Kabuki contou com a co-autoria de Lucia Santaella para culminar na mediação dessas relações que foi encontrada no teórico francês Jacques Lacan sobre o conceito de vazio a partir da subjetividade que se impõe ao sujeito.

\section{A dança Odissi}

De acordo com Andraus, Soares e Santos (2013), a dança indiana tem origem milenar e, segundo Ramm-Bonvitt (1987), existe comprovação de que há cinco milênios já se praticava dança na Índia:

Escavações em Mohenjo-Daro e em Harappa produziram provas concludentes de que a dança já era praticada na India 5.000 anos atrás. A figura de bronze de uma menina dançando, que foi desenterrada no início deste século, aponta para a tradição pré-ariana da dança. Essa figura representa possivelmente uma predecessora das dançarinas do templo (Devadasis). [...] A maioria dos pesquisadores vê os primórdios da dança clássica indiana nas danças mímicas que tinham lugar nas festas dos deuses, sobretudo nas festas cultuais de Krishna e de Shiva (Ramm-Bonwitt, 1987, p. 12, grifo nosso).

Originária da região leste da Índia, estado de Orissa, a dança clássica Odissi urgiu nos templos. É marcada por um estilo lírico de dança. A relação íntima experienciada na música é uma característica sobre a qual a estética do estilo é construída.

Por volta do século XVI d.C., existiam três tipos de bailarinas em Orissa: as maharis nos templos, as nachunis na corte e os gotipuas nos akhadas (ginásios), 
sendo os últimos os únicos que se apresentavam para o público em geral3. Segundo Andraus et al.:

Atualmente, considera-se a existência de sete estilos de dança clássica na Índia: Bharathanatyam, Kuchipudi, Mohiniyattam, Kathakali, Odissi, Manipuri e Kathak. O Odissi ramificou-se em três escolas: Mahari, ligada à tradição Devadasi, que diz respeito às bailarinas mulheres que dançam dentro dos templos para as divindades; Nartaki, que seria a tradição de Odissi que se desenvolveu nas cortes; e Gotipua, realizada por crianças do gênero masculino usando trajes femininos e interpretando papéis femininos (Andraus et. al., 2013, p. 77, grifos nossos).

A dança clássica Odissi acabou diferenciando-se dos demais estilos pelo uso do tronco, marcando uma sinuosidade que lhe é bastante peculiar. O trabalho de tronco aparece especialmente nas técnicas conhecidas pelo nome de tribhang (ou tribanga).

O conceito de tribhang divide o corpo em três partes: cabeça, busto e torso. Qualquer postura que articula estes três elementos é chamada tribhangi. Este conceito criou posturas muito características, que são mais contorcidas do que as encontradas em outros estilos clássicos de dança indiana (Courtney apud Andraus et al, 2013, p. 78).

Os tribangas caracterizam-se pelas suas formas arredondadas e, "por esta razão, associadas com o feminino". Já o "Bhangi seria o espaço vazio que se forma pelo abaulamento lateral do tronco, que se desloca em sentido oposto ao da cabeça e das pernas" (Andraus et al., 2012, p. 78, grifo nosso). Outra movimentação característica do Odissi são os choukas, que se caracterizam por serem mais retilíneos e, por sua vez, associados com o masculino; os também característicos mudras no Odissi são marcados por posturas "simbólicas das mãos que, dependendo de como são utilizadas no texto coreográfico, podem adquirir diferentes significados" (Ibidem). Assim, uma postura do corpo pode exprimir um sentimento particular, por assim dizer, uma expressão por si só, e os nomes relacionados a elas expressam aquele estado de espírito específico.

Os exercícios técnicos, como os Tribangas e os Choukas, são acrescidos de coreografias tradicionais praticadas por todo bailarino de Odissi. Uma delas é o Dashavatar, que, literalmente, significa "as dez encarnações de Vishnu". Na coreografia, são representadas as encarnações de Vishnu; por exemplo, Matsya (peixe), Kurma (tartaruga), Varaha (javali) e Narasimha (meio homem, meio leão). Vishnu é, para os hindus, "o deus que sustenta o mundo e é a personificação da misericórdia e da bondade, [...] tido por muitos hindus como a divindade universal" (Ramm-Bonwitt, 1987, p. 20).

O gestual da coreografia, composto pelos mudras, simboliza trechos da lenda retratada no Gita Govinda. Alguns mudras são utilizados em conjunto, como Alapadma (flor de lótus) sobre Mrigashirsha (cabeça do veado), utilizado para simbolizar Vishnu encarnado como javali sustentando o mundo. A codificação do Odissi, portanto, não é nem um pouco simples, pois os mudras,

${ }^{3}$ Fonte: http://trinayam.org/history. 
embora tenham significados, ganham sentido apenas na construção de cada texto coreográfico em particular. Diferentemente do que ocorre na dança ocidental, a interpretação, no Odissi, não é desvinculada da técnica, dado o fato de haver codificação até mesmo das posturas de cabeça e do olhar; isso, no entanto, não isenta o bailarino de, estando em cena, decidir como preencher os momentos vazios entre as marcações coreográficas - é assim que se estabelece seu papel como artista criador na obra, na esfera da interpretação (Andraus et al., 2013, p. 79, grifos nossos).

Trata-se, como se pode ver, de um tipo de dança altamente codificada e, portanto, uma dança carregada de simbolismos, em que cada gesto tem o poder de representar entidades cujos significados são culturalmente instituídos.

\section{Odissi e Kabuki: diálogos}

Segundo Martinez (2000), o Kabuki pode ser comparado às formas indianas de dança por seus aspectos de artes múltiplas integradas em uma forma única. $\mathrm{O}$ autor esclarece que "a palavra Kabuki deriva de três ideogramas chineses, ka, bu e ki, que significam, respectivamente, cantar, dançar e representar." (Martinez, 2000 , p. 1) Tendo surgido ao final do século XVI, patrocinado, sobretudo, pela classe comerciante, o Kabuki resultou de uma combinação de formas populares e clássicas; entre essas últimas, o Noh e o Kyogen: "Seu repertório inclui peças de todas essas tradições, assim como do Bunraku (teatro de bonecos). O Kabuki emprega três grupos musicais com funções distintas, nas quais se destaca o papel narrativo do Shamisen" (Ibidem).

Afirma ainda o autor que "a representação do Kabuki e a música que o acompanha desenvolveram-se por meio de um intenso processo de formalização, resultando em estruturas e formas sígnicas". (Ibidem) Ao mesmo tempo em que simbolizam ideias e ações, essas formas podem ser interpretadas de tal maneira que "[...] nada mais significam do que suas próprias qualidades, tal como na técnica do mie, quando o ator/dançarino de Kabuki congela a ação num momento de grande intensidade" (Ibidem).

Sem descartar as razões que Martinez encontra para marcar as analogias entre as diferentes formas da dança indiana e o Kabuki, o ponto de contato que buscamos entre ambas encontra-se na questão do vazio, traço central de diferenciação entre as culturas do Oriente e do Ocidente.

Segundo nos informa Cheng (1979, p. 25), a ideia do vazio na China existe desde o início de sua filosofia, expressa na obra sagrada e milenar $O$ livro das mutações, conhecido como I Ching. Nele se encontram as bases da sabedoria chinesa. I tem três significados: o fácil, o mutável e a constância. O fácil indica ausência de esforço. Seu poder encontra-se na mudança e seu estado, na constância. Tudo muda, menos a própria mudança que é constante (Wilhelm, 1973, p. 15).

Embora esteja presente em outras filosofias do Oriente, foi a escola taoista que fez do vazio seu elemento central. Constitui-se em fundamento da ontologia taoista, aquilo que vem antes do Céu e da Terra. Corresponde ao Não-ter, ao Nada, ao Vazio Supremo. Além do campo ontológico, o vazio também joga 
um papel importante nos domínios do mundo material. Portanto, o vazio não é apenas o estado supremo para cuja direção devemos tender, mas ele também se encontra no interior de todas as coisas, no coração mesmo de suas substâncias e de suas mutações (Cheng, 1979, p. 29).

Enfim, trata-se de uma filosofia fundamental que "propõe concepções precisas relativas à cosmologia, ao destino humano e à relação entre o ser humano e o universo". Assim, o vazio não pode ser entendido como algo vago ou inexistente, pois se trata de uma ideia eminentemente dinâmica e ativa que está ligada ao sopro vital e ao princípio de Yin-Yang, ou seja, ele se constitui como lugar por excelência onde se operam as transformações na busca da verdadeira plenitude (Ibidem, p. 21).

Esse conceito de vazio foi também explicitado por Bonfitto em A Pregnância do Vazio: o ensino e a prática do Kabuki (1994), ao tratar do trabalho do ator.

\footnotetext{
Num primeiro momento, o ator tem que se preocupar mais com a execução precisa dos movimentos. Só quando os movimentos forem assimilados é que $\mathrm{o}$ ator pode preencher as formas com a sua interioridade. Mas, mesmo durante o processo de assimilação das formas a interioridade já está presente num grau crescente. Quanto mais precisas são as formas executadas pelo ator, mais a sua interioridade poderá se manifestar (Bonfitto, 1994, p. 23).
}

Ainda segundo Bonfitto, o zen budismo teve um papel central no processo de criação japonesa nas diversas formas de arte. O que interessa ao autor, em especial, é o aprofundamento de um conceito crucial do zen, o conceito do vazio. Para o autor, "o objetivo do zen é desenvolver a percepção do vazio no momento em que ele se dá" (Ibidem). Mas de que vazio se trata?

O vazio para o zen é o estado da não elaboração da atividade mental, o mundo dualista é visto como o produto da obra subjetiva e arbitrária da mente humana. No zen, o infinito é representado simbolicamente, de forma finita e definida; o infinito é reduzido a um instante, à extensão limitada a um ponto, o máximo no mínimo. (Takeshita apud Bonfitto, 1994, p. 19)

Para Bonfitto, foi através do Yugen e do Wabi, dois meios das artes visuais japonesas, que a concretização estética do conceito do vazio emergiu. Essas técnicas, que não iremos aprofundar neste artigo, constituem um princípio estético marcado pelo vazio; "a forma é o vazio" (Ibidem, p. 20).

No teatro Kabuki, por exemplo, é possível identificar dois níveis de manifestação do conceito do vazio: o primeiro se dá na relação do ator com os objetos de/em cena e o segundo, nos processos que envolvem a assimilação e a reprodução das katas (formas). Nessa estrutura, o que é caracterizado por "espaço de interpretação" concretizaria o conceito através da presença do continuum denominado qualidade de energia. "O objeto em si passa a adquirir um significado, uma função, a partir da relação que o ator constrói recodificando-o a cada instante" (Ibidem).

Por meio da observação precisa e treinamento, Bonfitto conceituou dois níveis existentes nas ações. O primeiro caracteriza-se pelo Esqueleto Estrutural e o segundo como Qualidade de Energia. O Esqueleto Estrutural pode ser entendido 
como "todos os elementos que podem ser reproduzidos visualmente no espaço, os quais, um a um, poderiam ser denominados movimentos". A Qualidade de Energia, por sua vez, é marcada pelo modo como a ação é realizada, mediante "variações rítmicas, impulsos (início de uma ação) e contra impulso (passagem de uma ação à outra). A forma e a Kata seriam, portanto, o resultado das combinações possíveis entre esses dois níveis. Bonfitto constatou, ainda, que "o elemento, que fazia os movimentos aparentemente iguais transformarem-se a cada instante em movimentos diferentes, era a qualidade de energia" (Ibidem, p. 68).

Para compreender a relação entre o igual e o diferente, Bonfitto (Ibidem, p. 72) recorreu ao conceito de mimese como foi teorizado por Zeami, ator e teórico japonês. Trata-se de um conceito que envolve cinco fases ou princípios:

(a) imitação propriamente dita, em que o ator estuda o objeto com cuidado para recolher informações;

(b) verossimilhança implica a imitação verídica de um traço ou objeto elegante, não havendo esforço formal em direção à "elegância" em si;

(c) identificação significa que aquele que imita se integra ao objeto até se tornar com ele uma só coisa;

(d) essencialização implica colher e representar mimeticamente o objeto, tornando-o distinto dos outros;

(e) limitação sugere a não representação de sentimentos excessivos.

Assim, "o 'imitar', na cultura japonesa, contém no seu interior um espaço de interpretação". Esse espaço se encontra num "continuum correspondente ao nível de qualidade de energia", como mencionado acima. O movimento, por sua vez, corresponde "a cada elemento pertencente ao nível 'Esqueleto Estrutural' e se manifestaria em todo deslocamento físico dos corpos". Desse modo, a ação seria o produto da fusão entre o movimento e um traço pertinente do nível "Qualidade de Energia". Disso se pode concluir que o imitar envolveria

três trabalhos de pertinentização, além de conter um espaço de interpretação que consiste no espaço de elaboração do personagem por parte do ator. E as Katas, por sua vez, não seriam formas rígidas, mas, apesar da precisão exigida no processo de execução, conteriam um espaço flexível, um espaço vazio (Ibidem, p. 72).

A questão do zen como caminho do vazio, tal como entendido no taoísmo e nas suas aplicações na arte, até aqui explicitada, remete-nos ao conceito lacaniano do vazio, um conceito que nos parece bastante oportuno para amarrar a experiência vivida da dança Odissi e da relação estabelecida por Martinez entre - Kabuki e as danças indianas. De fato, Lacan também trabalhou o conceito do vazio dentro de uma teorização próxima do zen, conforme será discutido abaixo.

\section{Lacan e o zen, ou o zen lacaniano?}

Para introduzir a questão à luz de Lacan, é preciso notar que o zen, esse movimento de pensamento budista, implantado no Japão nos séculos XII e XIII, na sua transmissão, apresenta algumas características fundamentais, como a do ensino direto de mestre a aluno e a busca por uma iluminação interior, ca- 
paz de libertar das ilusões do sensório e dos excessos do racionalismo. Para atingir a coincidência espontânea com a essência do ser, é necessária a prática da meditação, de certas posturas corporais, do trabalho manual e da pobreza voluntária. Vale ainda notar que "o ensino do zen reside para além das palavras. Para os mestres do zen, atividades como beber, caminhar, praticar tiro com arco tornam-se ritos, isto é, meios capazes de ajudar a encontrar a sua via" (AMORIM, 2007, p. 196).

Lacan, em seu primeiro seminário, afirma que:

O mestre interrompe o silêncio por qualquer coisa, um sarcasmo, um pontapé. É assim que procede na busca do sentido um mestre budista, segundo a técnica zen. São os próprios alunos que devem buscar a resposta às suas próprias questões. O mestre não ensina ex cathedra uma ciência pronta, ele traz a resposta quando os alunos estão a ponto de encontrá-la. Esse ensino é uma recusa de todo sistema. Ele descobre um pensamento em movimento pronto no entanto, para o sistema, pois necessariamente apresenta uma face dogmática (Lacan, [1953-1954] 1975, p. 7).

Por que Lacan inicia esse Seminário com essa fala sobre a técnica zen? A pergunta que surge é: o que teria a psicanálise a ver com a técnica zen? $\bigcirc$ trecho é curto, mas já é capaz de nos indicar que a lição do mestre budista é não ensinar "ex-cathedra uma ciência já pronta, pois a resposta aparecerá uma vez que os alunos estejam a ponto de encontrá-la. É assim que o mestre conduz seus discípulos pelo percurso que os leva à resposta". Mas ao estilo de Lacan, esse convite conduz a nós, intérpretes de seus textos, ao jogo da decifração. Lacan não é mestre. A técnica zen, afirma ele, possui um limite: o de manter o dogma intacto. O mestre zen já possui a resposta, apenas aguarda, pacientemente, que seu discípulo esteja preparado para ouvi-la.

O que conta ao analista é um estado zen de disponibilidade ao inesperado e a presença de espírito que advém de sua escuta flutuante para pontuar o que se deixa falar. A técnica zen é assim um meio que o mestre aplica para permitir ao discípulo a experiência espiritual de revelação e iluminação (Sartori). Não se trata para o discípulo de compreender ou decifrar o Ko-an (Kung-an), uma espécie de problema proposto pelo mestre, pois esse problema aponta para o sem sentido, o que lança o sujeito na busca de uma resposta inédita (Monteiro, 2012).

Na psicanálise lacaniana e no zen-budismo, existe uma correlação que nos inclina a tomar uma direção desconstrutiva em relação ao sofrimento do sujeito. Não se busca fornecer sentidos para esse sofrimento, mas insiste-se no confronto com o limite do saber, com o sem-sentido da existência e seu vazio para o qual não há outra vazão senão a do silêncio. Para Lacan, a arte também se alimenta desse logos, o do vazio. Há sempre um nada que pulsa, num insinuante insistir em dizer a que veio. Segundo Gonçalves (2012, p. 47), trata-se de um vazio "que concebe, metaforicamente, os mistérios da criação nas mãos do ceramista que envolve o vazio para criar o vaso, evocado desde sempre por quem se aventura a refletir sobre o assunto da criação". Para o autor, a função do vaso encontra-se no vazio que ele cria, justamente para introduzir a perspectiva de preenchê-lo. 
Nas palavras de Lacan (2008, p. 147), nas quais a autora se apoia, "O vazio e o pleno são introduzidos pelo vaso num mundo que, por si mesmo, não conhece semelhante. A partir desse significante modelado, que caracteriza o vaso, o vazio e o pleno entram como tais no mundo, nem mais nem menos, e com o mesmo sentido". Gonçalves completa:

O vaso para estar pleno, primeiramente, em essência, é vazio. Se considerar-se o vaso como um objeto feito para representar a existência do vazio no centro do real, esse vazio, tal como ele se apresenta na representação, apresenta-se exatamente como nada. É por isso que o oleiro cria o vaso, cria-o a partir do furo (Gonçalves, 2012, p. 48).

Assim, a atividade artística pode ser entendida como uma maneira de sublimar a falta, uma forma paradoxal de costurar o vazio. Nessa medida, podemos pensar que toda arte possui, portanto, relação com o vazio. Todavia, há, tanto na arte contemporânea, como na dança e no teatro, a perturbadora intenção de dar forma ao vazio, como se, mostrando escancaradamente o nada, fosse possível livrar-se da falta original. É por isso que, segundo Wirthmann (2007), a obra de arte pode ser vista como um contorno, um modo de apontar, ainda que de lado, para das Ding (a Coisa em si que, segundo Kant, é incognoscível).

Das Ding está sempre sob um véu. Há sempre algo de intangível na obra de arte, algo de certa forma mítico, impossível, assim como na Coisa, das Ding, que é essencialmente a Outra coisa. A Coisa numa relação com o Outro não barrado e, portanto, mítico. Talvez por isso o objeto se ausenta e, ao mesmo tempo, se presentifica dentro das particularidades de cada obra de arte (Wirthmann, 2007).

\section{No vazio dos treinamentos}

A arte emerge onde o aprendiz desaparece? O corpo responde ali onde a cena não se encena? O vazio é capaz de formar ou é a forma que é vazia na aceleração constante do aluno ocidental? Essas são algumas questões que nos fizeram refletir na posição do aprendiz diante do vazio. Vazio marcado aqui pela forma, insinuante delicadeza dos contornos corporais, tão manipulavelmente desobedientes do apreensivo corpo em movimento.

Tanto no Kabuki como na Odissi, o vazio segue a lógica da forma por meio de construções recodificadas a cada instante em cena. Artistas capazes de abrir lacunas para o corpo aparecer. Sujeito que se desprende da cena ali protagonizada para o artista surgir.

Após as aulas com Marília Vieira, relatarei a seguir, a partir do meu próprio processo de formação nessa imersão de inverno, minhas observações e vivências pontuadas pelo vazio em meio ao processo.

A constante preocupação com a execução precisa dos movimentos e a velocidade de entendimento eram os protagonistas dessas aulas. Sair de uma aula sem compreender a complexidade daqueles movimentos. Isso não era possível. Depois de ter passado por tantas escolas, tantos cursos e workshops, por que se 
sobressaia a insistência em não conseguir fazer os mudras? Por que nos chowkas, as dores musculares se acentuavam, uma vez que vem de técnicas de sapateado muito mais pesadas? O compasso dos cantes sempre descompassados num corpo aflito. Imitar apressadamente. Não escutar a fala do mestre. Mas, junto com a dor muscular, a calma se apressou. Pressa da calma. Calma depressa. O corpo cansado rendeu-se aos ensinamentos. Foi domado pelo físico. Deixou o mental partir. O corpo se rendeu ao lento passo do compasso. Compasso que pulsa no furo do corpo. Na falta, o vazio emerge. Falta que faz furo na arte. Vazio que cria e recria formas. Formas que se reinventam na solidão do vazio que demanda.

Nos sete intensos dias com duração de 8 horas/aula de técnica de aquecimento e coreografias da Odissi, me recordo que as primeiras aulas de repetição consecutiva aos movimentos do professor se davam de maneira assustada e apressada. As coreografias não se condensavam nesse corpo como unidade, mas sim como passos soltos envoltos em uma técnica muito detalhada e rebuscada. A premissa, naquele momento, era a de imitar por imitar, não entendia o que estava sendo feito pelo corpo e tampouco o que estava sendo narrado. As diferenças entre as gestualidades eram uma incógnita. A fala da professora-guru se fazia presente. "Repita. Repita. Repita". Mostrava os exercícios em seu corpo, no nosso corpo. Pedia calma. Pedia repetição. Pedia contentamento no ato da execução. Apreciava o corpo cansado. Domado à força.

Após cinco dias de intenso treinamento, esse emaranhado gestual, essa narrativa distante, esses detalhes gestuais esboçavam-se num corpo dolorido. A busca de um sentido, sem que com isso as formas se alterassem, ver a mesma coreografia por diferentes bailarinos, e escutar a história narrada, depois de repeti-la diversas vezes, começava a dar pistas de uma pré-elaboração corporal.

Uma narrativa, ainda tão insipiente, assim como a criança em seu momento de apropriação da linguagem, se fazia presente. Os movimentos começavam a ser assimilados e, assim, podia lentamente, bem devagar, tentar preencher as formas com a interioridade. Quanto mais precisas as formas se tornavam, mais a interioridade se manifestava. Depois da imitação, começava a dar sentido às ações. Chegar pela busca da precisão à própria sensibilidade. Era esse o caminho. Percurso vazio. Solitário. Assim como o percurso de uma psicanálise. Preencher o espaço que pede forma. Deixar-se rabiscar. Possibilitar ir e voltar num caminho sem garantias. Ora, não seria esse o mais instigante desejo do artista? Percorrer sem testemunhas? Percorrer.

\section{Tempo de Concluir}

Os ensinamentos advindos do Oriente carregam algo de misterioso ao Ocidente. Coisa a se decifrar. Esconderijo a que poucos têm acesso. Provavelmente a chave secreta do labirinto, tanto nos ensinamentos orientais, no baile flamenco, como também em um percurso analítico, ao camuflarmos o vazio, a forma aparece. A tendência é a de colorirmos algo que ainda não experimentou a mistura de cores. Treinamento que, de alguma forma, carrega um traço de sabedoria, lá onde a ignorância deveria imperar. Não saber é autorizar o corpo a criar. Criar 
pulsação. Criar ritmo. Voltar às origens mais tenras. Mas, para tanto, é preciso renunciar. Denunciar as fraquezas ao suportar o vazio que preenche. Vazio de espera. Tempo de interiorizar. Apropriar e largar.

Será que não é disso de que se trata o treinamento? De um tempo de maturar. De ludibriar. De fazer de conta e permitir que o universo lúdico nos invada, num contorno sem precedentes. Tempo lógico de Lacan? Longo tempo de escuta até que o compasso pulse? Tempo de observação ao que da narrativa corporal da dança Odissi remeterá àquele sujeito?

Questões que poderão ser respondidas, e se é que há respostas para elas, somente depois de vivenciar no corpo as transgressões a que se submete aquele que aceita o convite.

\section{Referências}

ANDRAUS, M. B. M.; SOARES, M. V.; SANTOS, I. F. Gestualidade da dança clássica Odissi e dança contemporânea ocidental: interfaces. Sala Preta Eletrônica (USP), v. 13, p. 71-82, 2013.

AMORIM, Fernando de. Tradução: Procopio Abreu. As implicações psíquicas da cirurgia estética. Tempo Psicanalítico. Rio de Janeiro, v. 39, p.195-224, 2007.

BONFITTO, Matteo. A Pregnância do vazio. O ensino e a prática do Kabuki: uma tentativa de modelização. São Paulo, Bologna: ECA/USP, Universidad de Bologna, 1994.

CHENG, François. Vide et Plein. Le Langage Pictural Chinois. Paris: Seuil, 1979.

GONÇALVES, Adriana Honorato. Questões Preliminares sobre Aspectos do Vazio na Arte Contemporânea. São Paulo. 2012 (Dissertação de Mestrado). Instituto de Artes, Universidade Estadual Paulista.

LACAN, Jaques. O Seminário, Livro 11: os Quatro Conceitos Fundamentais da Psicanálise. Rio de Janeiro: Zahar, 1988.

LACAN, Jaques. O Seminário, Livro 7: a Ética da Psicanálise. Rio de Janeiro: Zahar, 2008.

MARTINEZ, José Luiz. Projeto de pesquisa Fapesp, vinculado ao Programa de PósGraduação em Comunicação e Semiótica e a Faculdade de Comunicação e Artes do Corpo. São Paulo, 2000. Disponível em: http://www.pucsp.br/cos/rism/muda-d.htm. Acesso em: 20 jun. 2013.

MONTEIRO, Cleide. A prática lacaniana e o princípio da imprevisibilidade, 2012. Disponível em: http://ebp.org.br/wp-content/uploads/2012/08/. Acesso em: 12 nov. 2013.

WILHELM, Helmut. Eight Lectures on the I Ching. Tradução de Cary F. Baynes. Prince- 
ton, NJ: Princeton University Press, 1973.

WIRTHMANN, Renata. Contorno e vazio uma leitura lacaniana sobre a arte, 2007. Disponível em: http://arteesubjetividade.wordpress.com/2007/08/16/. Acesso em 12 nov.2013.

Recebido em 22/05/2014

Aprovado em 23/06/2014 